\title{
THE ASSOCIATION BETWEEN INTERNALIZED AND EXTERNALIZED PROBLEM BEHAVIOR AMONG SLOVAK EARLY ADOLESCENTS
}

\author{
Lucia Hricová1, Maria Bacikova-Sleskova ${ }^{1}$, Ol'ga Orosová $^{1}$, \& Lenka Abrinková ${ }^{2}$ \\ ${ }^{1}$ Department of Educational Psychology \& Health Psychology, Faculty of Arts, PJ Safarik University in \\ Kosice, Moyzesova 9, 04001 Kosice (Slovakia) \\ ${ }^{2}$ Department of Psychology, Faculty of Arts, PJ Safarik University in Kosice, Moyzesova 9, 04001 Kosice
} (Slovakia)

\begin{abstract}
Background: Current research findings regarding risk behavior have suggested examining the association between externalized problem behavior (EPB) and internalized problem behavior (IPB). This submitted work explores a set of IPB as factors which increase the likelihood of specific EPB.

Aim: To assess the impact of IRB such as body dissatisfaction, bulimic symptoms and drive for thinness on EPB such as alcohol use, cigarette smoking and marihuana use.

Methods: The sample size consisted of 1180 pupils $(50.1 \%$ girls; mean age $=12.99 ; \mathrm{SD}=.77)$ from all regions in Slovakia. The children were administered questionnaires to monitor EPB - alcohol use, tobacco or electronic cigarette smoking, marihuana use and IRB - dive for thinness, bulimic symptoms (Eating disorder inventory), body dissatisfaction (Children body image scale).

Results: Three separate models of logistic regression were performed to assess the impact of IRB factors on the likelihood that respondents would report EPB: (1) alcohol use, (2) cigarette smoking, (3) marihuana use. The models containing interactions of gender and independent variables were significant. Model 1: Being male and bulimic symptoms increased the likelihood of alcohol use. Moreover, the interaction between gender and the drive for thinness indicated that the association between alcohol use and the drive for thinness was significant among girls but not among boys. Model 2: Bulimic symptoms increased the likelihood of cigarette smoking. The interaction between gender and the drive for thinness had the same character as Model 1. Model 3: Being male and the drive for thinness increased the likelihood of marihuana use. The interaction effect of gender and body dissatisfaction on marihuana use has the same character as interactions in Models 1 and 2.

Conclusions: IPB increases the likelihood of EPB in early adolescents. The significant interactions suggest that a higher drive for thinness among girls places them in the group of potential alcohol users and cigarettes smokers whereas there is no effect of the drive for thinness on males. The interaction effect of body dissatisfaction and gender is similar in the case of marihuana use. The current results contribute to previous findings and might be beneficial in preventing ERB in early adolescents.
\end{abstract}

Keywords: Externalized problem behavior, internalized problem behavior, early adolescents, drive for thinness, bulimic symptoms.

\section{Introduction}

Problem behavior is commonly defined as a behavior contravening social norms and inadequate regarding the developmental level (Jessor \& Jessor, 1997). Thus, it is a problem perceived from the perspective of society as well as causing serious psychosocial or physical harm to the individual behaving problematically (Nielsen, Sobotková et al., 2014). Problem behavior can take different forms of maladaptive behavior from minor offenses against discipline to aggressive and destructive behavior (Labáth, 2001). Apart from the mentioned externalized forms of problem behavior manifesting externally and associated with violations of norms and aggressive behavior, experts have also defined internalized forms (Wadsworth et al., 2001). Internalized problems are a broad class of co-occurring problems typical for internal emotional distress, such as depressive symptoms, anxiety, worry, sadness and hopelessness. On the other hand, externalized problems are related to conflict with others and social mores (Eshrat, 2016). Issues on body image, body dissatisfaction and problems with eating/ emotional eating could be considered as specific forms of internalized behaviors as they are mostly associated with depressive symptoms and inner emotional distress. Early adolescents are in a period of significant changes in psychological and social development (Oshio et al., 2003). As such, this is a typical time for problem behavior growth and body image concerns (Vágnerová, 2005). The desire to have a perfect body image 
and the preoccupation with one's own body has become popular among young people also in Slovakia (Krch, 2005). Unsurprisingly, the period of early adolescence is potentially risky for body dissatisfaction and even for the outset of dysfunctional eating (Smolak, Levin, \& Schermer, 1999). Problem behavior in adolescents occurs quite often and could negatively affect their education, job chances and social relationships, resulting in a reduced quality of life (Jaspers et al.., 2012; Kessler, 2001). Therefore, it is essential to understand the factors associated with the development of problem behavior in early adolescence before more serious problems occur.

\section{Objectives}

Current research findings regarding problem behavior suggest looking at the association between externalized and internalized problem behavior (Colder, Frndak, Lengua, et al., 2018) as well as considering potential moderating variables (Scalco et al., 2014). The submitted work explores a set of internalized problem behavior as factors increasing the likelihood of specific externalized problem behaviors. The aim is to assess the impact of internalized problem behavior such as body dissatisfaction (BD), bulimic symptoms (BS), drive for thinness (DFT) on externalized problem behavior such as alcohol use, cigarettes smoking and marihuana use.

\section{Methods}

\subsection{Research sample and procedure}

The sample size consisted of 1180 pupils (50.1\% girls; mean age=12.99; $\mathrm{SD}=.77$ ) from all regions in Slovakia. The data was collected using paper-pen questionnaires from early adolescents in the seventh grade at primary schools in Slovakia in the school year 2017/2018. Prior to this, informed consent was obtained from the parents/legal representatives of all participants. 24 primary schools from all regions in Slovakia were included in the analyses in this study. In each school, pupils from all classes in the seventh grade participated in the study. The questionnaires were filled in during two school lessons in the presence of a trained research team member, without the presence of the teacher. The questionnaires were completed confidentially. The study obtained ethical approval from the university's ethics committee.

\subsection{Measurements}

Child's alcohol, marihuana use and smoking

The prevalence of alcohol use, smoking cigarettes and using marihuana during the past 30 days was measured on a frequency scale with the options: not at all/ once/ twice-four times/ five times or more (Hibell et al, 2012). The answers were dichotomized in order to differentiate the sample between alcohol, marihuana and cigarette users and non-users. In the case of alcohol, those who had only tried alcohol once were defined as non-users.

The drive for thinness

The Drive for Thinness Subscale of Eating Disorders Inventory (EDI, Garner et al., 1982) has seven items (e.g.: "I am terrified of gaining weight.") and indicates excessive concern with dieting, preoccupation with weight and entrenchment in the extreme pursuit of thinness. The items reflect both an ardent wish to lose weight as well as a fear of weight gain. These are the fundamental features of anorexia nervosa and considered to be indicators of disordered eating.

Bulimia symptoms

The Bulimia symptoms subscale of Eating Disorders Inventory (EDI, Garner et al., 1982) is a seven-item scale that assesses impulsive eating patterns and purgative use. The example of item is: "I have gone on eating binges where I have felt that I could not stop."

Body dissatisfaction

The Children's Body Image Scale (Truby \& Paxton, 2002) consists of seven drawings of a female/male figure (for female/male participants) each increasing in size. Each child was asked to identify the body figure most like their own (perceived figure). They were then asked to nominate the body figure they would most like to have (ideal figure). The difference between the category number of their perceived and ideal figures was used as a measure of body size dissatisfaction (i.e. perceived-ideal discrepancy). In addition, an absolute discrepancy score was derived.

\subsection{Statistical analyses}

In order to address the aim of the research, a descriptive analysis, Chi-square test of independence and Mann-Whitney $U$ test were performed in SPSS 21 to test the gender differences. Non-parametric tests were chosen due to the character of the variables (categorical), the abnormal distribution of the variables and the unbalanced numbers of respondents in each of the two groups. 
Logistic regression was computed to test the associations between externalized and internalized problem behavior.

\section{Results}

Gender differences were found in all types of internalized problem behavior. Girls reported a significantly higher drive for thinness, body dissatisfaction and more bulimia symptoms in comparison to boys. On the other hand, the results on externalized forms of problem behavior did not reveal any significant association between problem behavior and gender (Table 1).

Table 1. Gender differences in examined variables.

\begin{tabular}{|l|l|l|l|l|l|}
\hline $\begin{array}{l}\text { Internalized problem } \\
\text { behavior }\end{array}$ & $\begin{array}{l}\text { Mean Rank } \\
\text { (boys/girls) }\end{array}$ & $\mathrm{N}$ (boys/girls) & $\mathrm{U}$ & $\mathrm{Z}$ & $\mathrm{p}$ \\
\hline Drive for thinness & $454,73 / 597,77$ & $521 / 532$ & 100935 & $-7,64$ & $<.001$ \\
\hline Bulimia symptoms & $509,65 / 581,74$ & $548 / 542$ & 128864 & -3.804 & $<.001$ \\
\hline Body dissatisfaction & $423,32 / 533,74$ & $459 / 502$ & 88733,5 & $-6,46$ & $<.001$ \\
\hline $\begin{array}{l}\text { Externalized problem } \\
\text { behavior }\end{array}$ & never used & used & $\chi^{2}$ & $\mathrm{df} / \mathrm{n}$ & $\mathrm{p}$ \\
\hline Alcohol use & $975(82.6 \%)^{*}$ & $205(17.4 \%)$ & 1.97 & $1 / 1129$ & .16 \\
\hline Smoking & $1066(90.3 \%)$ & $114(9.7 \%)$ & 2.16 & $1 / 1129$ & .14 \\
\hline Marihuana use & $1088(92.2 \%)$ & $92(7.8 \%)$ & 1.47 & $1 / 1129$ & .23 \\
\hline
\end{tabular}

Note. *never used or only tried once

Three separate models of logistic regression were performed to assess the impact of internalized risk behavior factors (BD, BS, DFT) on the likelihood that respondents would report externalized risk behavior: (1) alcohol use, (2) cigarette smoking, (3) marihuana use. The models containing gender- interactions were significant, (1) $\chi^{2}(4,1030)=53.04, p<.001$; (2) $\chi^{2}(4,1030)=34.59, \mathrm{p}<.001$; (3) $\chi 2(4,906)=20.46, p<.001$, which indicates that the models were able to distinguish between those who reported externalized risk behavior and those who did not. Each model as a whole explained between 5\% and $9 \%(1) ; 3.3 \%$ and $9 \%(2) ; 2.2 \%$ and $9.3 \%$ (3) of the variance in the respective risk behavior and correctly classified $85.7 \%$ (1); $93,7 \%$ (2); $96.9 \%$ (3) of cases. The single statistical values of each model are all reported in Table 2.

Table 2. Logistic regression predicting likelihood of externalized risk behaviour.

\begin{tabular}{|c|c|c|c|c|c|c|}
\hline & \multirow[t]{2}{*}{ B } & \multirow[t]{2}{*}{ df } & \multirow[t]{2}{*}{ Odds Ratio } & \multirow[t]{2}{*}{$\mathrm{p}$} & \multicolumn{2}{|c|}{ 95.0\% C.I. for Odds Ratio } \\
\hline & & & & & Lower & Upper \\
\hline \multicolumn{7}{|c|}{ Model 1. Alcohol use } \\
\hline Bulimic symptoms & .10 & 1 & 1.11 & $<0.001$ & 1.07 & 1.14 \\
\hline Drive for thinness & -.001 & 1 & 1 & .95 & .96 & 1.04 \\
\hline Gender* & -1.34 & 1 & .26 & $<0.05$ & .10 & .67 \\
\hline Interaction gender-DFT & .04 & 1 & 1.05 & 0.55 & .999 & 1.09 \\
\hline \multicolumn{7}{|c|}{ Model 2. cigarette smoking } \\
\hline Bulimic symptoms & .09 & 1 & 1.10 & $<0.001$ & 1.05 & 1.14 \\
\hline Drive for thinness & -.02 & 1 & .98 & .47 & .92 & 1.04 \\
\hline Gender* & 1.32 & 1 & .27 & .07 & .07 & 1.10 \\
\hline Interaction gender-DFT & .08 & 1 & 1.08 & $<0.05$ & 1.01 & 1.16 \\
\hline \multicolumn{7}{|c|}{ Model 3. marihuana use } \\
\hline Body dissatisfaction & -.30 & 1 & .74 & .29 & .43 & 1.29 \\
\hline Drive for thinness & .08 & 1 & 1.08 & $<0.05$ & 1.02 & 1.13 \\
\hline Gender* & -2.36 & 1 & .10 & $<0.05$ & .02 & .41 \\
\hline Interaction gender-BD & .83 & 1 & 2.3 & $<0.05$ & 1.16 & 4.56 \\
\hline
\end{tabular}

Note. *girls as the reference group, $\mathrm{df}=$ degrees of freedom, C.I.=confidence interval, significant results are in bold, DFT- drive for thinness, BD - body dissatisfaction

Alcohol use was significantly explained by bulimic symptoms and gender while the interaction between gender and the drive for thinness was on the edge of significance. Being male and bulimic symptoms increased the likelihood of alcohol use. Moreover, the interaction effect indicated that girls who belong to the group of potential alcohol users scored higher in the drive for thinness compared to non-using alcohol girls. Boys scored similarly regardless of the group of alcohol users. Thus, it could be said that the association between alcohol use and the drive for thinness was significant among girls but not among boys (Figure 1). 
Smoking was significantly explained by bulimic symptoms and the interaction between gender and the drive for thinness. Bulimic symptoms increased the likelihood of smoking. The interaction effect indicated the same trend in the association between the drive for thinness and smoking among boys and girls as in the model for alcohol use. Girls who belong to the group of potential smokers scored higher in the drive for thinness in comparison to non-smoking girls. Boys scored similarly regardless of the group of cigarettes users (Figure 2).

Marihuana use was significantly explained by the drive for thinness, gender and the interaction between gender and body dissatisfaction. Being male and the drive for thinness increased the likelihood of marihuana use. Moreover, the interaction effect indicated a significant association between body dissatisfaction and marihuana use among girls, but not among boys. Girls who belong to the group of potential marihuana users reported higher body dissatisfaction compared to non-using marihuana girls. Boys scored similarly regardless of the group of marihuana users (Figure 3 ).

Figure 1. Interaction graph for alcohol use.

Figure 2. Interaction graph for smoking.

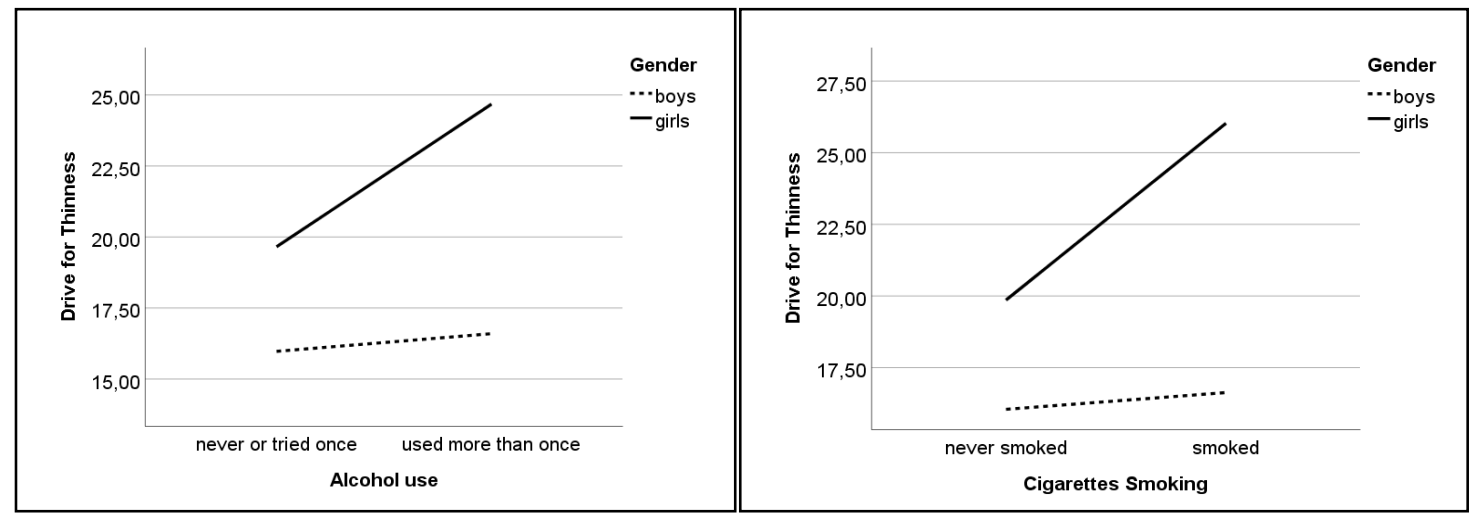

Figure 3. Interaction graph for marihuana use.

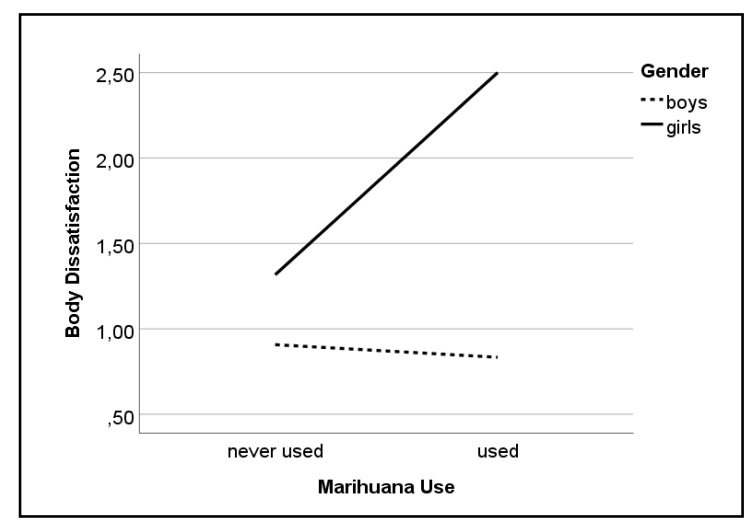

\section{Discussion and conclusions}

Bulimic symptoms increased the likelihood of alcohol use and smoking cigarettes. Being male significantly increased the likelihood of alcohol and marihuana use. The drive for thinness only appeared to be significant in the model of marihuana use. The significant interactions suggest that the higher drive for thinness among the girls place them in the risk group for alcohol use and smoking although there is no effect of drive for thinness on males. The interaction effect of body dissatisfaction and gender is similar in the case of marihuana use. Previous studies have shown that internalized problem behavior such as anxiety, depression or somatic complaints are negatively related to cigarette smoking in early adolescence, while in middle and late adolescence the association is positive (Aloise-Young, Zaleski, \& Swaim, 2017;). The co-occurrence of other externalized symptoms increases the protective effect of internalized problem behavior on alcohol but not marihuana use (Colder, Frndak, Lengua, et al., 2018). The current study has brought different results. Internalized problem behavior such as bulimic symptoms are not only positively associated with smoking but also with alcohol use among early adolescent girls and boys. In addition, smoking marihuana was associated positively with the drive for thinness according to the current results. This inconsistency might be explained by a different type of internalized problem behavior. It seems that problems connected to dysfunctional eating indicate higher levels of externalized problem behavior. Furthermore, there is evidence of gender specificity in the context of externalized and internalized problem behavior which could also stand behind the significant gender interactions revealed 
by the current findings. Girls are hypothesized to have lower rates of externalized problem behaviors during early to middle childhood when compared to boys. On the other hand, girls are theorized to have more internalized problems than boys. This could be explained by more risk factors such as gender role stereotypes, stronger interpersonal orientation or childhood anxiety which predisposes them to depressive symptoms (Eshrat, 2016). This is also consistent with the gender differences found in the current study. Girls reported more internalized but less externalized problem behavior than boys. In the context of the interaction effect of gender, girls were found to score higher on externalized problems when also reported higher internalized problems. This might also be explained by their specific social development which is influenced by social appearance standards. There could also be other factors not examined in this study which explain the explored associations. These include interpersonal and self-critical vulnerabilities, self-concept, stress and quality of relationships with parents and peers etc. The current results contradict previous findings on the associations between externalized and internalized problem behavior. They contribute to current research knowledge and urge future examination which might be also beneficial for preventing externalized problem behavior of early adolescents.

\section{Acknowledgements}

This work was supported by the scientific grant agency of the Ministry of Education, Science, Research and Sport of the Slovak Republic and of Slovak Academy of Sciences under contract no. VEGA 1/0523/20 and by the Slovak Research and Development Agency under the contract no. APVV-15-0662.

\section{References}

Aloise-Young, P.A., Zaleski, A.C., \& Swaim, R.C. (2017). A Longitudinal Examination of the Relation Between Internalizing Problem Behaviors and Early Adolescent Cigarette Smoking. Journal of Dual Diagnosis, 13(1), 73-79.

Colder, C.R., Frndak, S., Lengua, L.J. et al. (2018). Internalizing and Externalizing Problem Behavior: A Test of a Latent Variable Interaction Predicting a Two-Part Growth Model of Adolescent Substance Use. J Abnorm Child Psychol 46, 319-330.

Eshrat, A. (2016). Internalizing and Externalizing Problems in Adolescents Analyzing the Gender Difference. International Journal of Research in Social Sciences, 6(1), 328-337.

Garner, M.D., Olmstead, M.P., \& Polivy, J. (1982). Development and Validation of a Multidimensional Eating Disorder Inventory for Anorexia Nervosa and Bulimia. Int'l Journal of Eating Disorders, 2(2), 15-34.

Hibell, B., Guttormsson, U., Ahlström, S., Balakireva, O., Bjarnason, T., Kokkevi, A., \& Kraus, L. (2012). The 2011 ESPAD report. Substance use among students in, 36 European Countries. Stockholm: Modintryckoffset AB, ISBN 978-91- 7278-233- 4.

Jaspers, M., De Winter, A. F., Huisman, M., Verhulst, F. et al. (2012). Trajectories of psychosocial problems in adolescents predicted by findings from early well-child assessments. Journal of Adolescent Health, 51(5), p.475-483.

Jessor, R., \& Jessor, S. L. (1977). Problem behavior and psychosocial development: A longitudinal study of youth. New York, New York Academic Press.

Kessler, R. C. et al. (2001). Mood disorders in children and adolescents: an epidemiologic perspective. Biological psychiatry, 49(12), 1002-1014.

Krch, F. D. (2005). Poruchy př́limu potravy. [Eating disorders.]. Praha: Grada Publishing.

Nielsen Sobotková, V. et al (2014). Rizikové a antisociální chování v adolescence. [Risk and antisocial behavior in adolescence]. Praha: Grada Publishing.

Oshio, A., Kaneko, H., Nagamine, S., \& Nakaya, M. (2003). Construct validity of the adolescent resilience scale. Psychological Reports, 93(3), 1217-1222.

Smolak, L., Levine, M. P., \& Schermer, F. (1999). Parental input and weight concerns among elementary school children. International Journal of Eating Disorders, 25, 263-271.

Scalco, M. D., Colder, C. R., Hawk, L. W., Read, J. P., Wieczorek, W. F., \& Lengua, L. J. (2014). Internalizing and externalizing problem behavior and early adolescent substance use: a test of a latent variable interaction and conditional indirect effects. Psychology of addictive behaviors: journal of the Society of Psychologists in Addictive Behaviors, 28(3), 828-840.

Truby. H. \& Paxton, S.J. (2004). Development of the Children's Body Image Scale. Br J Clin Psychol, 41(2), 185-203.

Vágnerová, M. (2005). Vývojová psychologie I.: dětství a dospívání. [Developmental psychology I.: childhood and adolescencel. Praha: Karolinum.

Wadsworth, M.E., Hudziak, J.J., Heath, A.C., Achenbach, T.M. (2001). Latent Class Analysis of Child Behavior Checklist Anxiety/Depression in Children and Adolescents. Journal of the American Academy of Child \& Adikescent Psychiatry, 40(1), p.106-114. 